www.jmscr.igmpublication.org

Impact Factor (SJIF): 6.379

Index Copernicus Value: 79.54

ISSN (e)-2347-176x ISSN (p) 2455-0450

crossrefDOI: https://dx.doi.org/10.18535/jmscr/v6i12.180

Journal Of Medical Science And Clinical Research

IGM Publication

An Official Publication of IGM Publication

\title{
Giant Pleomorphic Adenoma of Parotid Gland: An Unusual Case Presentation
}

\author{
Authors \\ Dr Biplab Mishra ${ }^{*}$, Dr Pratyusha Priyadarshini², Snehasis Pradhan ${ }^{3}$ \\ Dr Afroza Firodous ${ }^{4}$, Dr Ram Niranjan kumar ${ }^{5}$, Dr Sekhar Kar ${ }^{6}$ \\ ${ }^{1}$ Junior Resident, SCB Medical College and Hospital, Cuttack, Odisha, India \\ ${ }^{2}$ Mch Resident JJ hospital, Mumbai, India \\ ${ }^{3}$ Senior Resident, AIIMS Bhubaneswar, India \\ 4,5,6 Junior Resident, SCB Medical College and Hospital, Cuttack, Odisha, India \\ Corresponding Author \\ Dr Biplab Mishra \\ S.R. Hostel Room No.181, SCB Medical College and Hospital, Cuttack, Odisha, India \\ Email: biplab14111988@gmail.com
}

\begin{abstract}
This a case of 40 years old male presenting to our department with a large swelling in the left side of neck associated with dragging sensarion. After clinical evaluation it wsa a giant smass in left submandibular margin extending tupto $4^{\text {th }}$ intercostals space.MRI neck showed a heterogenous soft tissue mass embedding left parotid and its parietal plane with slight compression and displacement of great vessels. FNAC indicated pleomorphic Adenoma of parotid gland. The patient ultimately underwent resection of the mass, which measured $26 \mathrm{~cm}$ in diameter, weighed $7.5 \mathrm{~kg}$, and proved on pathologic examination to be a benign mixed tumor without malignant degeneration. Management of this unusual tumour is discussed, and the literature on giant parotid tumours is reviewed.
\end{abstract}

\section{Introduction}

Of all salivary gland tumours arising in the parotid gland, $85 \%$ are benign; of these, $80 \%$ are pleomorphic adenoma $\stackrel{1}{ }$. These tumours are almost uniformly characterised by a slow-growing, painless mass, usually varying from 2 to $6 \mathrm{~cm}$ in diameter when resected $\stackrel{2}{2}$. In $4 \%$ of cases, tumours may be malignant

Cases of giant pleomorphic adenomas have been reported in the parotid gland, presenting as an irregular multinodular mass that can weigh more than $8 \mathrm{~kg}^{3}$. Most cases of giant adenomas were seen before the 1980s, but some have been published recently ${ }^{4}$. Given the relative ease of diagnosis of pleomorphic adenomas based on clinical and cytological findings, and the low risk of malignant degeneration, some authors have an expectant management policy for those patients who do not desire surgery ${ }^{1}$. This is in contrast to traditional management, which emphasises that "aggressive treatment of primary and recurrent mixed tumours is necessary" $\underline{5}$ due to their malignant potential.

This paper describes an unusual case of a giant pleomorphic adenoma arising in the parotid gland, along with the reasons for diagnostic delay. This case and others like it demonstrate that aesthetic and 
social morbidity is sufficient to justify, when possible, early tumour excision should be carried out.

\section{Case Report}

A 40 year old male, presented with a large swelling in left side of the neck associated with dragging sensation. No history of pain, fever, difficulty in swallowing or breathing. Patient noticed the swelling $11 \mathrm{yrs}$ back which gradually increased in size. He Neglected it for almost 10yrs, mainly due to lack of symptoms \& poor health care and weak financial status.

$\mathrm{C} / \mathrm{E}$-showed a giant spherical mass of size $20 \times 14 \times 16 \mathrm{~cm}$ in the Left submandibular region extending upto Left $4^{\text {th }}$ intercostal space. Swelling was firm in consistency with small areas showing fluctuation (cystic), multinodular. Carotid pulsation intac $\mathrm{t}$ and no signs of facial palsy and non tender. No restriction in movement at temporomandibular joint. Cervical lymph nodes not palpable.

MRI of neck was performed which showed a heterogenous soft tissue mass embedding Left Parotid \& its Parietal Plane with slight compression and displacement of great vessels.

FNAC report indicated Pleomorphic Adenoma of the Parotid.

The tumour was excised after raisng skin flaps with a team of plastic and gen surgeons under General anaesthesia. A clean plane of dissection was achieved and adjacent vital structres were found to be normal with no local invasion. Mass involved only the superficial lobe of parotid and it was dissected out with preservation of facial nerve.Patient was dischrged on pod 6 without any post op complication.In follow up(pod12) patient presented with wound dehiscence which was secondarily closed after mobilization, and final stich removal was done on $20^{\text {th }}$ post op day. NO other complication found in next two visits.

\section{Discussion}

Although uncommon, cases of giant pleomorphic adenomas have been described the majority of which involved the parotid gland. The first case of giant pleomorphic adenoma published in medical literature was reported by Spence in $1863^{6}$, who described the treatment of a mixed tumour $>1 \mathrm{~kg}$. In most of the cases described in the literature, the lack of information and patient's negligence are considered as the most relevant aspects influencing the treatment delay. The incidence of malignant transformation in adenomas ranges from $1.9 \%$ to $23.3 \%$. Some authors postulated that the risk of malignant transformation increases from $1.6 \%$ in tumours with less than 5 years of evolution, to $9.5 \%$ for those presenting for more than 15 years.

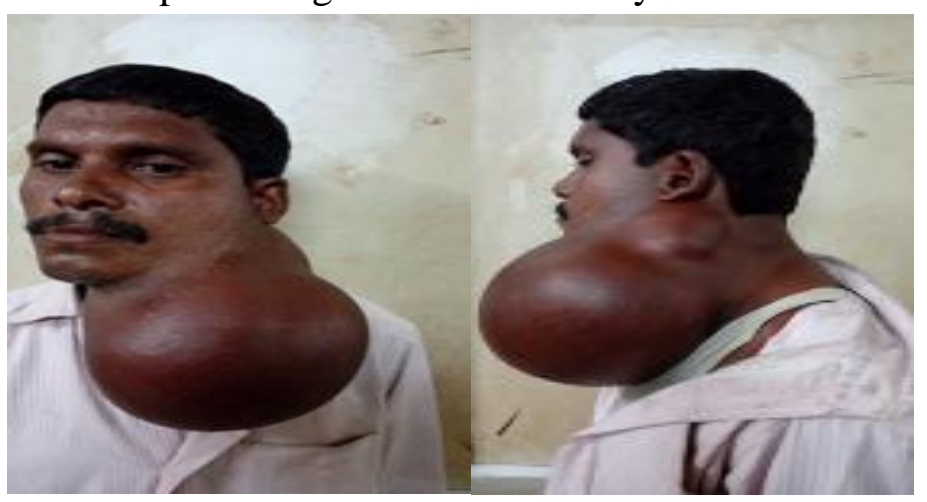

Figure 1: AP and lateral view of the tumour pre-op
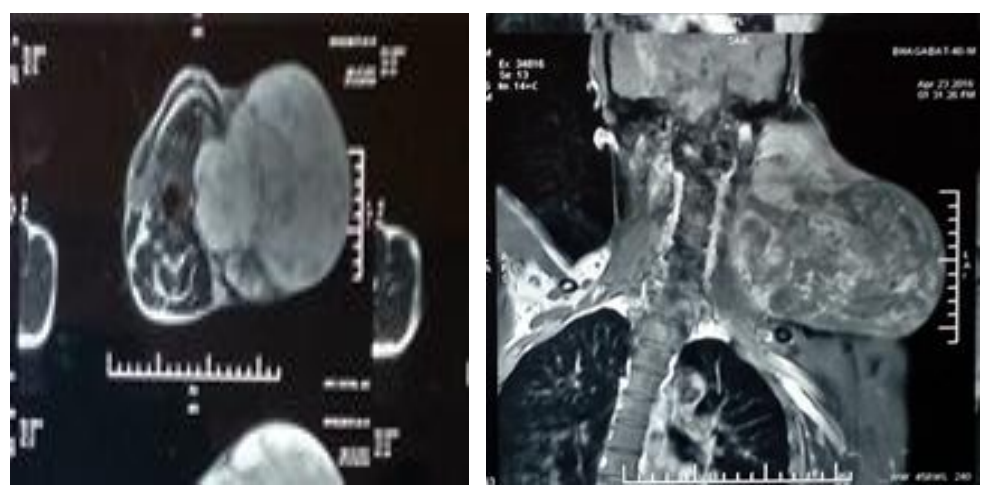

Figure 2: MRI images showing heterogenous enhancement and cystic degeneration at posterior pole.

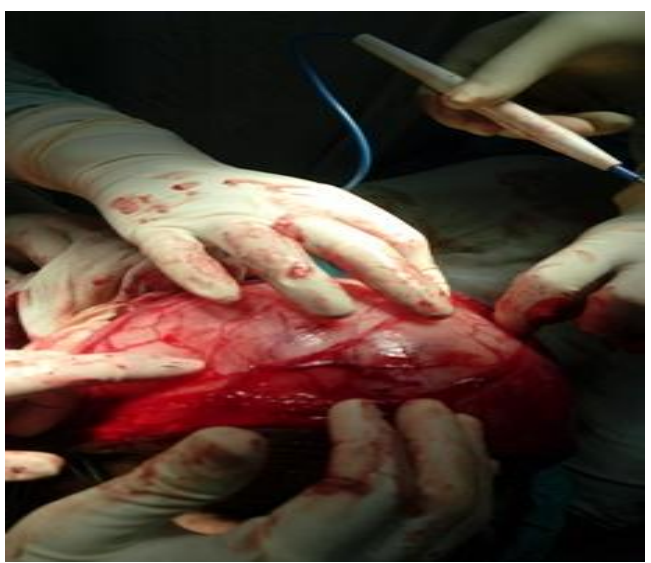

Figure 3 


\section{JMSCR Vol||06||Issue||12||Page 1105-1108||December}

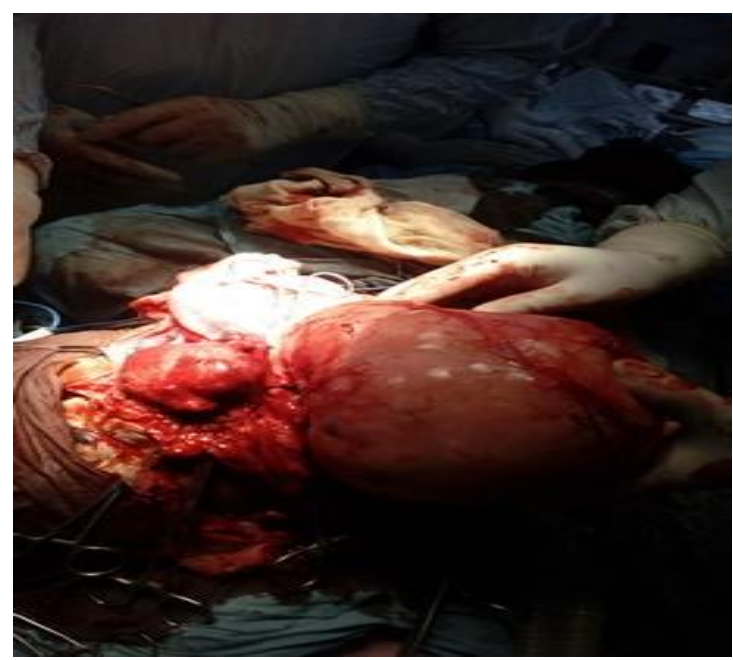

Figure 4 A clean plane of dissection achieved in fig 3 and 4,with total mass dissected out.

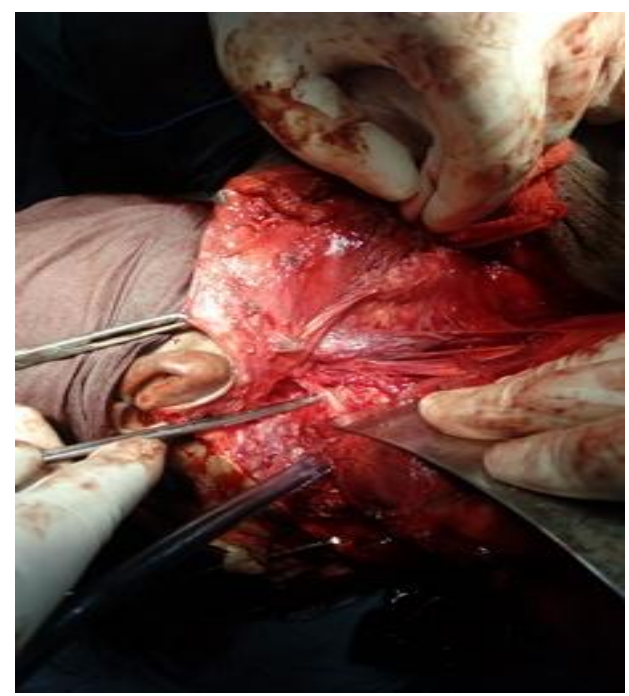

Figure 5: facial nerve seen in fig 5 which was preserved.

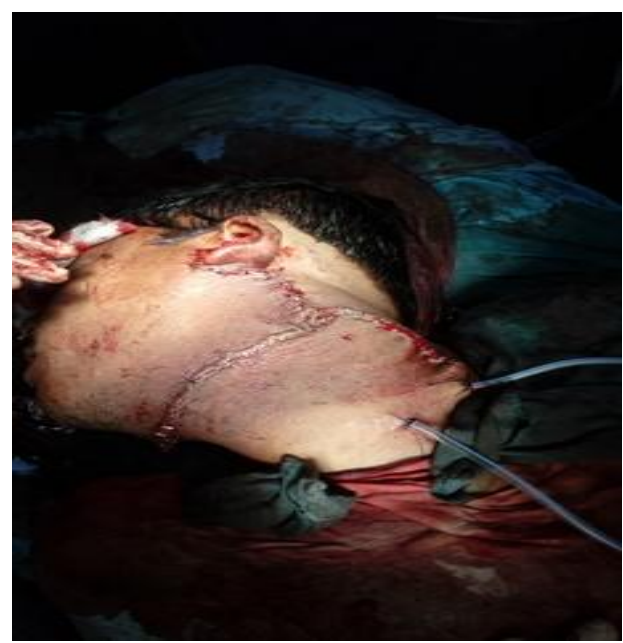

Figure 6: Post op view after skin flap closure.

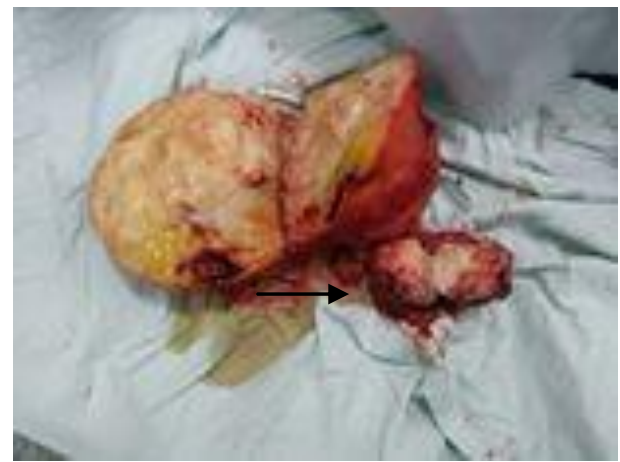

Figure 7: showing the Macroscopic view of the tumour with arrow showing area of cystic degeneration.

\section{Conclusion}

Neglecting even a benign parotid tumour carries an increasing risk of facial nerve injury when treatment is performed. The bony and muscular deformity associated with such tumours is uniformly disfiguring and incapacitating. Although it is generally accepted that the majority of all giant adenomas remain non-malignant, this case and others like it should serve to remind us that the clinical course of these masses can be far from benign. Documentation on the nature of the lesion, and an early surgical management could limit its incidence.

\section{Acknowledgement}

Authors acknowledge all their colleagues and juniors for their kind help and cooperation.

Funding: No funding sources

Conflict of interest: None declared

Ethical approval: The study was approved by the institutional ethics committee

\section{References}

1. Phillips DE, Jones AS. Reliability of clinical examination in the diagnosis of parotid tumors. JR Coll Surg Edinb. 1994;392:100102. [PubMed]

2. Buenting JE, Smith TL, Holmes DK. Giant pleomorphic adenoma of the parotid gland: case report and review of the literature. Ear Nose Throat J. 1998;77:634-634. 637-8, 640. [PubMed] 
3. Ellis GL, Auclair PL, editors. Atlas of tumor pathology. Tumours of the salivary glands. Washington, DC: Armed Forces Institute of Pathology; 1995. pp. 39-41.

4. Honda T, Yamamoto Y, Isago T, et al. Giant pleomorphic adenoma of the parotid gland with malignant transformation. Ann Plast Surg. 2005;55:524-527. [PubMed]

5. Duck SW, McConnel FM. Malignant degeneration of pleomorphic adenoma. Clinical implications. Am J Otolaryngol. 1993;14:175-178. [PubMed]

6. Spence J. Case of enormous deep-seated tumour of the face and neck, successfully removed by operation plates. The Dublin Journal of Medical Science. 1863;36:272283.

7. Short DW, Pular P. Giant parotid tumors: with report of a case. J Roy Coll Surg (Edinburgh) 1956;3:240-248. [PubMed]

8. Schultz-Coulon HJ. Pleomorphic giant adenomas of the parotid gland. Laryngorhinootologie. 1989;68:445-449. [PubMed]

9. Auclair PL, Ellis GL. Atypical features in salivary gland mixed tumors: their relationship to malignant transformation. Mod Pathol. 1996;9:652-657. [PubMed]

10. Yamamoto Y. Clinical signs and histology of carcinoma in pleomorphicadenoma. Otologia. 1994;87:1320-1324.

11. Eneroth CM, Zetterberg A. Malignancy in pleomorphic adenoma. A clinical and microspectrophotometric study. Acta Otolaryngol. 1974;77:426-432. [PubMed]. 